\title{
Klippel-Trenaunay Syndrome: A Rare Cause of Vaginal Bleeding in the Prepubescent Girl
}

\section{Laila Essabar, Siham Amenzouy, Fatima Zohra Oudghiri, Lamia Kerboubi, Badr Sououd Benjelloun Dakhama*}

Department of Paediatric Medical Emergency_Children's Hospital of Rabat-Ibn Sina, University Hospital Center, Faculty of Medicine and Pharmacy of Rabat, Mohammed V University, Rabat, Morocco

Email: `bsououd@gmail.com

How to cite this paper: Essabar, L., Amenzouy, S., Oudghiri, F.Z., Kerboubi, L. and Dakhama, B.S.B. (2016) Klippel Trenaunay Syndrome: A Rare Cause of Vaginal Bleeding in the Prepubescent Girl. Journal of Biosciences and Medicines, 4, 1-7. http://dx.doi.org/10.4236/jbm.2016.411001

Received: August 27, 2016

Accepted: October 30, 2016

Published: November 4, 2016

Copyright $\odot 2016$ by authors and Scientific Research Publishing Inc. This work is licensed under the Creative Commons Attribution International License (CC BY 4.0).

http://creativecommons.org/licenses/by/4.0/

\begin{abstract}
Klippel-Trénaunay syndrome (KTS) is an uncommon congenital disorder with unknown etiology that consists of mixed vascular malformations. Visceral organs may also be involved leading to a variety of manifestations. Although seemingly uncommon, genital tract involvement can occur and be a source of significant morbidity. We hereby describe a case of KTS of a 7-year-old female patient presenting with genital bleeding, large venous and capillary malformations and soft tissue hypertrophy of right limb. Patient was treated conservatively and asked to follow-up regularly. KTS should be kept on mind as a cause of vaginal bleeding in preteen girls especially those with suggestive clinical features. Management of this complex condition is challenging because of its progressive nature and wide range of disease severity.
\end{abstract}

\section{Keywords}

Klippel Trenaunay Syndrome, Vascular Malformation, Soft Tissue Hypertrophy, Genital Bleeding, Child

\section{Introduction}

Klippel-Trénaunay syndrome (KTS), or angioosteohypertrophy syndrome, is a rare congenital malformation syndrome [1] characterized by three clinical features, namely cutaneous capillary malformations (port-wine stain), venous varicosities, and soft tissue and/or bony hypertrophy of the extremity [2]. The etiology of KTS remains unclear many authors believe it to be caused by an embryonic developmental disorder of mesodermal tissues that affects angiogenesis at different stages, possibly following intrauterine insult [3].

It is a sporadic condition with multifactorial inheritance. There is no predilection for 
gender or any particular ethnicity; more and more cases are now being seen at birth, childhood or adolescence. The purpose of this paper was to present a case of KTS as a rare cause of genital bleeding in a preteen girl, and to highlight the clinical and imaging features of the disease.

\section{Case Report}

A seven year old female child presented to our department with the chief complaint of cyclical genital bleeding. No histories of similar complaints in siblings, traumatism, or any other bleeding manifestations were noted. All milestones were normal for age.

On physical examination, the weight and height were normal, the back and the proximal left thigh exhibited a large erythematous patch with characteristic port-wine stain capillary malformations (Figure1). The right lower limb and the right labia majora were hypertrophic (Figure 2). Hymen was intact. In measuring both the lower limbs, they were found to be of equal length. In addition, we noted multiple vascular malformations extensively involved the buttocks, thighs, legs, feet and genitalia (Figure 2 Figure 3). No venous ulcers were present. The assessment of pubertal showed Tanner stage 0 .

Laboratory investigations showed the following: hemoglobin was $13 \mathrm{~g} / \mathrm{dL}$, white blood cell and platelet counts were normal, coagulation tests showed no abnormalities.

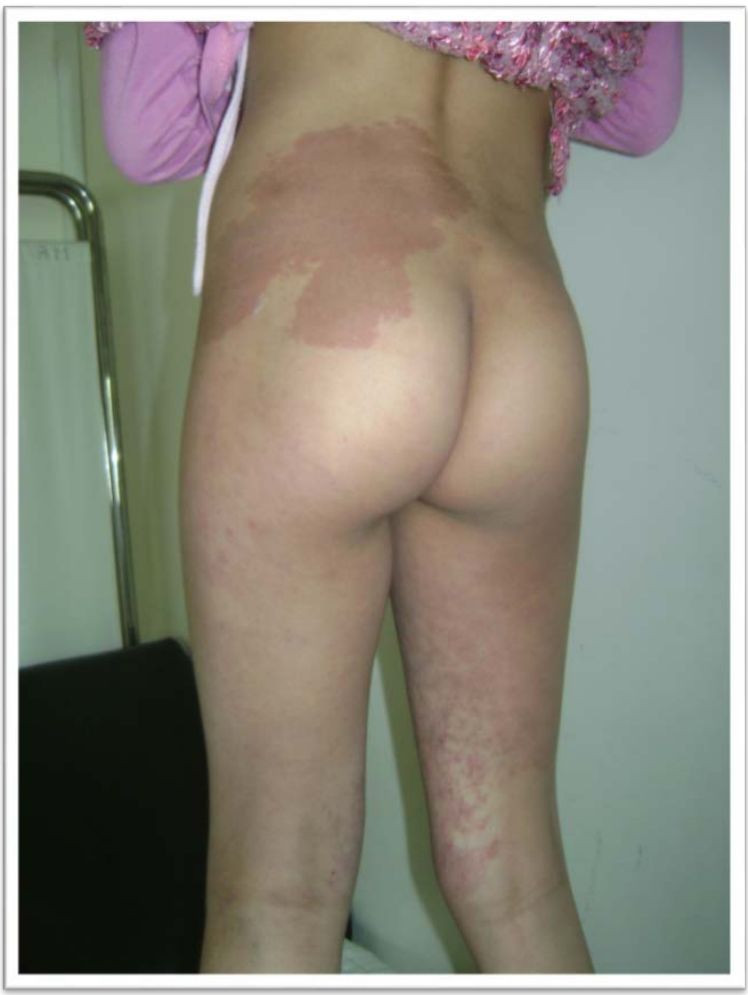

Figure 1. A large erythematous patch with characteristic port-wine stain capillary malformations covering the back and the proximal left thigh. 


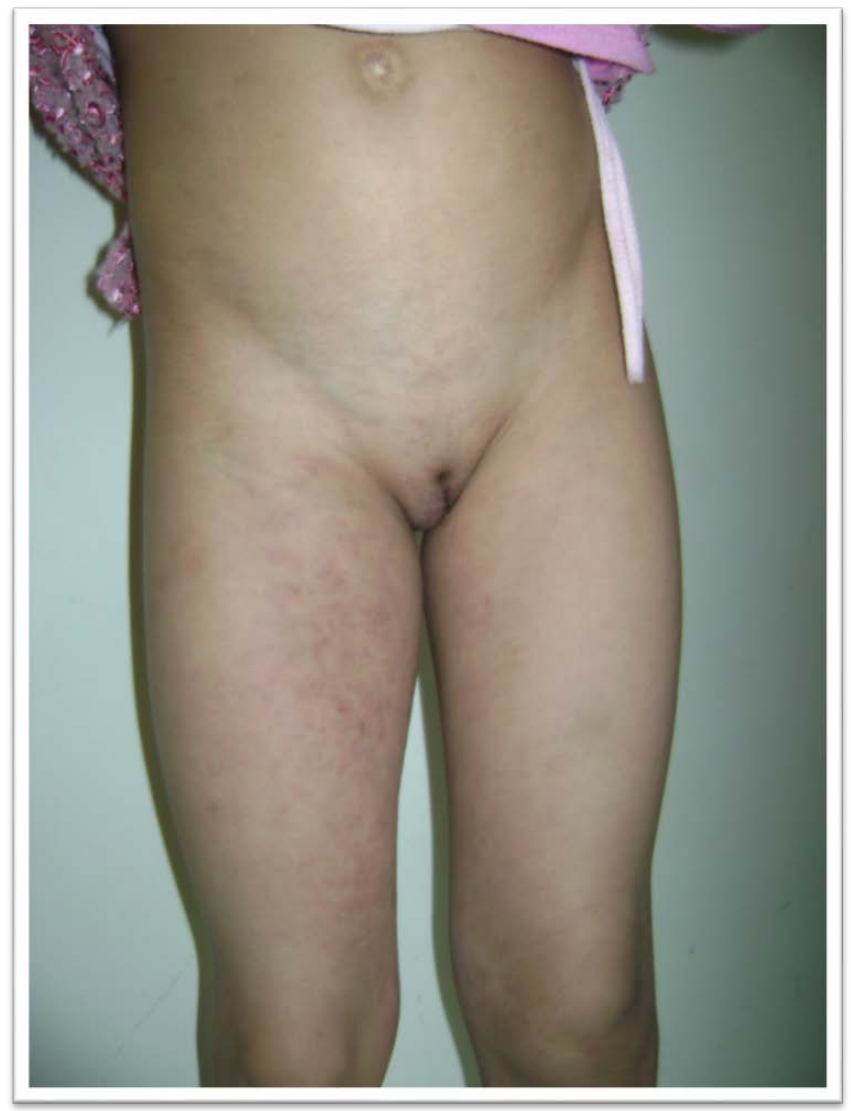

Figure 2. Hypertrophy of the right labia majora and the soft tissues of the lower limb. Note the multiple vascular malformations involving the thighs and genitalia.

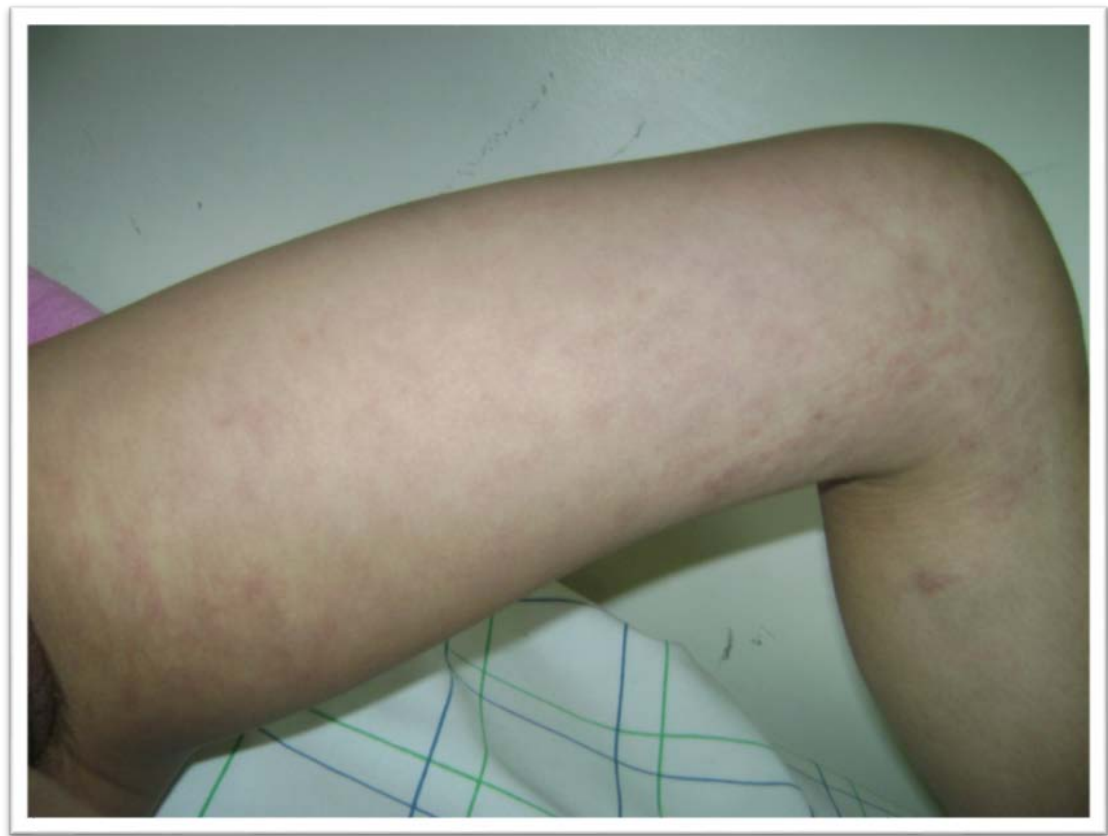

Figure 3. Multiple vascular malformations involving the thighs and legs. 
The pubertal stage, the absence of advance growth and pelvic ultrasound data allowed excluding the diagnosis of true precocious puberty. Abdominopelvic ultrasound was performed to rule out an ovarian or adrenal tumor and showed vascular malformations involving uterine cervix. Magnetic resonance imaging and angiogram revealed multiple pelvic vascularized malformations involving the cervix and uterus and continuing into the rectum; the thighs and the lower limbs (Figure 4, Figure 5). On the basis of these typical findings, the child was diagnosed as having KTS with visceral involvement. Treatment was conservative. The patient is now on regular follow up.

\section{Discussion}

Diagnosis of KTS is based on the triad of capillary malformation, venous malformation and soft tissue hypertrophy which have been found to occur in $98 \%, 72 \%$ and $67 \%$ of children with KTS respectively [4]. Our case presented with all of the three abovementioned major clinical features.

The lesions can involve the lower or upper limbs and rarely the trunk. Occasionally, KTS patients may present with symptoms such as hematuria and/or hematochezia when an internal organ is associated [5]. The different organs involved are gastrointestinal tract, genitourinary tract, and central nervous system. Bleeding from rectum and bladder is life threatening and is an emergency condition, it has a reported incidence of around $1 \%[6]$. Our patient presented with genital bleeding secondary to the involvement of the uterine cervix.

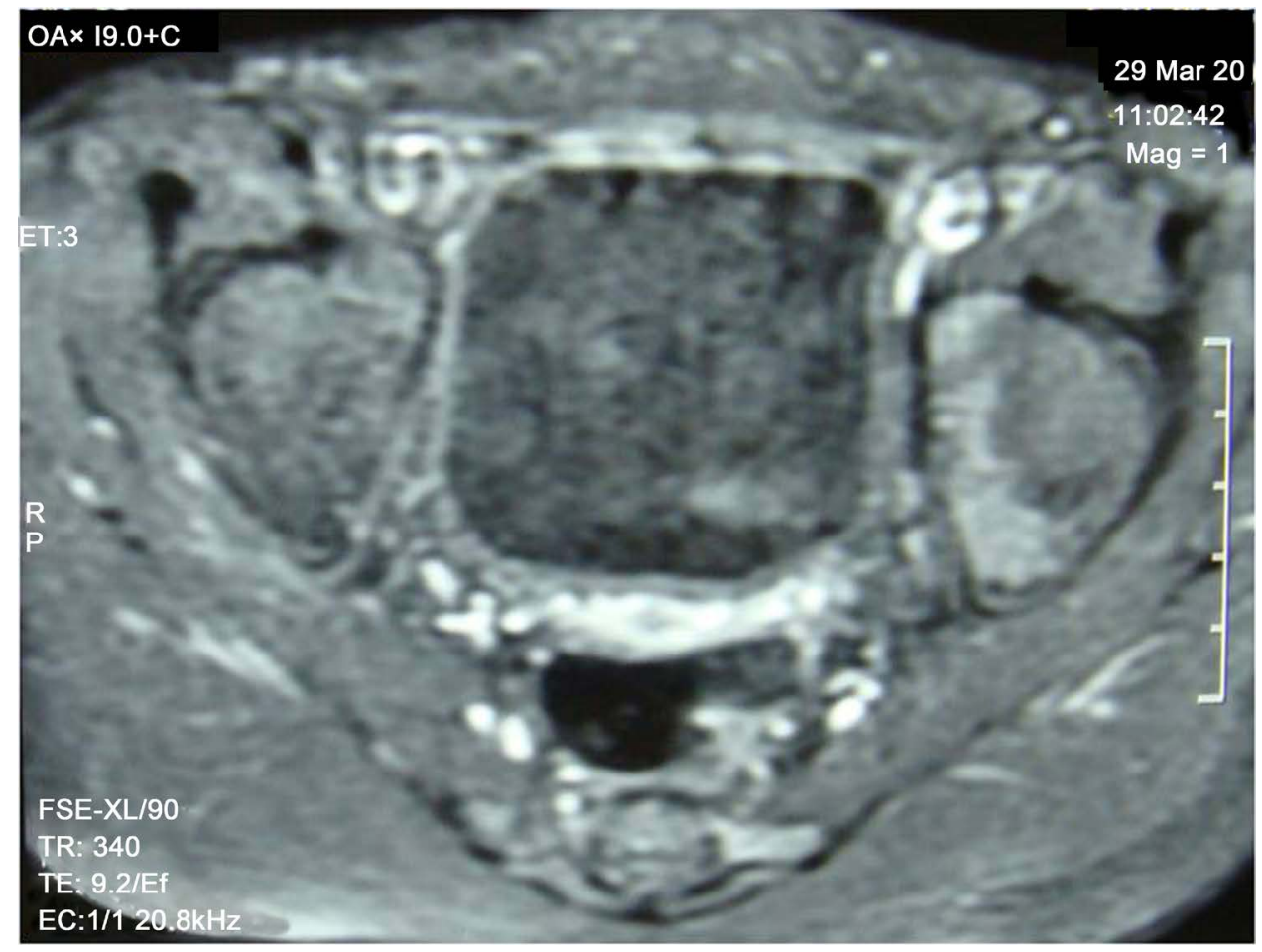

Figure 4. Axial pelvis MRI view showing multiple vasculari zed malformations involving the cervix and uterus and continuing into the rectum. 


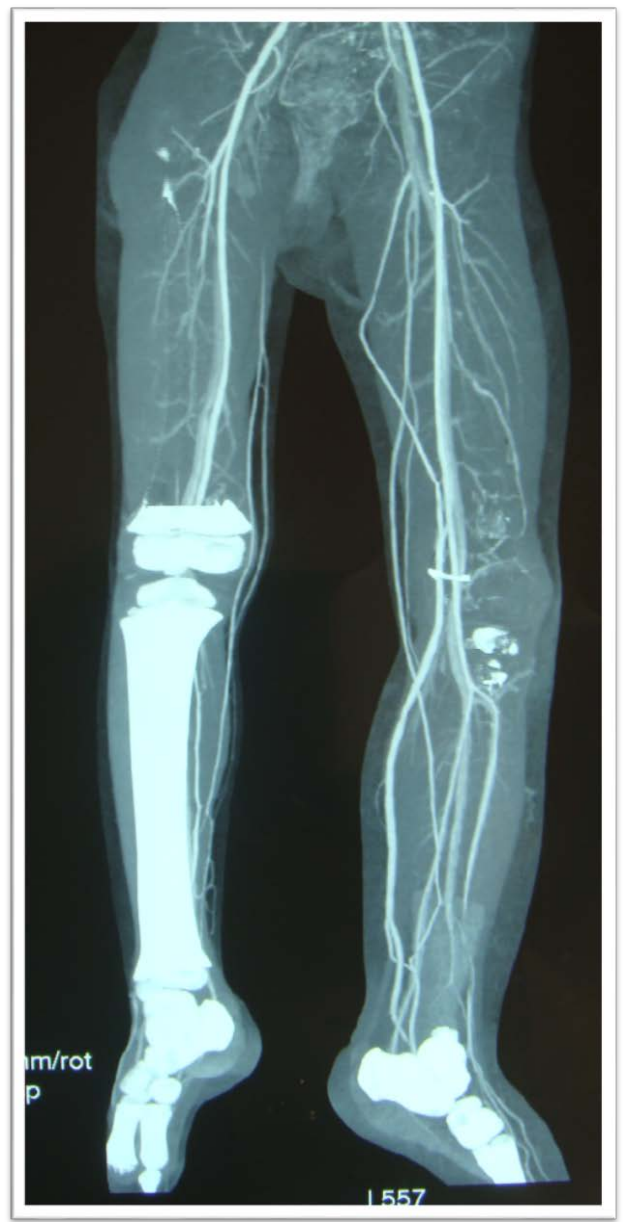

Figure 5. Magnetic resonance angiogram showing multiple vascularized malformations involving the thighs and the lower limbs.

Diagnosis of KTS is done by examination of the patient clinically, but usually, confirmation requires laboratory studies, such as higher D-dimer assay, gene analysis of AGGF1, and radiological imaging such as x-ray study of lower limb bones, color Doppler of arteries and veins, MRI, MR angiography, and catheter angiography can be considered. Ultrasound, CT, and MRI show the presence of soft tissue hypertrophy in KTS and can also identify the associated various vascular malformations present throughout the branch. These imaging modalities can also identify the involvement of vascular lesions in the pelvis and abdomen, in our patient pelvic MRI revealed multiple pelvic vascularized malformations involving the cervix and uterus and continuing into the rectum and thighs.

The complications of KTS include thrombophlebitis, deep venous thrombosis, pulmonary embolism, and congestive heart failure. There has been case reports of KTS presenting with life-threatening hematochezia and symptoms of iron deficiency anemia as an outcome of gastrointestinal vascular malformations [7] [8]. KTS can also present as renal hemangioma with complicating perirenal hematoma requiring nephrectomy 
[9]. There has been a case report of pulmonary vascular malformations of KTS leading to thromboembolism [10] and leading to death of the patients [11].

Management of KTS is dependent upon individual symptoms, it is mainly supportive and symptomatic, Surgical procedure is used only in very distressing cases [12]. The patient needs regular follow-up to the medical personnel and also regular radiological monitoring. Our patient was treated conservatively with compression therapy, special orthopedic footwear, and lifestyle adjustment to improve the use of the limb, she is on regular follow-up.

\section{Conclusion}

Klippel-Trénaunay syndrome is an uncommon yet distinct clinical entity. It can involve multiple organ systems, and the patients can have visceral organ complications. The management of KTS is challenging and multidimensional. It should be cautious, and regular follow-up of the patients is to be taken care of. More researches are requested to better understand the pathogenesis of the disease and to provide new therapeutic possibilities.

\section{Conflicts of Interest}

All the authors have no conflicts of interest to disclose.

\section{Ethics Statement}

Written informed consent was obtained from the patient's parents for publication of this case report and any accompanying images.

\section{References}

[1] Suman, S., Sinha, A.K., Kumari, S., et al. (2015) Klippel Trenaunay Syndrome: A Case Report. Journal of Evolution of Medical and Dental Sciences, 4, 5981-5985. http://dx.doi.org/10.14260/jemds/2015/871

[2] Sung, H.M., Chung, H.Y., Lee, S.J., Lee, J.M., et al. (2015) Clinical Experience of the Klippel-Trenaunay Syndrome. Archives of Plastic Surgery, 42, 552-558. http://dx.doi.org/10.5999/aps.2015.42.5.552

[3] Baskerville, P.A., Ackroyd, J.S. and Browse, N.L. (1985) The Etiology of the KlippelTrenaunay Syndrome. Annals of Surgery, 202, 624-627. http://dx.doi.org/10.1097/00000658-198511000-00015

[4] Jacob, A.G., Driscoll, D.J., Shaughnessy, W.J., Stanson, A.W., Clay, R.P. and Gloviczki, P. (1998) Klippel Trénaunay Syndrome: Spectrum and Management. Mayo Clinic Proceedings, 73, 28-36.

[5] Husmann, D.A., Rathburn, S.R. and Driscoll, D.J. (2007) Klippel-Trenaunay Syndrome: Incidence and Treatment of Genitourinary Sequelae. The Journal of Urology, 177, 1244-1249. http://dx.doi.org/10.1016/j.juro.2006.11.099

[6] Cha, S.H., Romeo, M.A. and Neutze, J.A. (2005) Visceral Manifestations of KlippelTrénaunay Syndrome. Radiographics, 25, 1694-1697. http://dx.doi.org/10.1148/rg.256055042

[7] Samo, S., Sherid, M., Husein, H., Sulaiman, S., Yungbluth, M. and Vainder, J.A. (2013) 
Klippel-Trenaunay Syndrome Causing Life-Threatening GI Bleeding: A Case Report and Review of the Literature. Case Reports in Gastrointestinal Medicine, 2013, Article ID: 813653. http://dx.doi.org/10.1155/2013/813653

[8] Wang, Z.K., Wang, F.Y., Zhu, R.M. and Liu, J. (2010) Klippel-Trenaunay Syndrome with Gastrointestinal Bleeding, Splenic Hemangiomas and Left Inferior Vena Cava. World Journal of Gastroenterology, 16, 1548-1552. http://dx.doi.org/10.3748/wjg.v16.i12.1548

[9] Schofield, D., Zaatari, G.S. and Gay, B.B. (1986) Klippel-Trenaunay and Sturge-Weber Syndromes with Renal Hemangioma and Double Inferior Vena Cava. The Journal of Urology, 136, 442-445.

[10] Aggarwal, K., Jain, V.K., Gupta, S., Aggarwal, H.K., Sen, J. and Goyal, V. (2003) KlippelTrenaunay Syndrome with a Life-Threatening Thromboembolic Event. The Journal of Dermatology, 30, 236-240. http://dx.doi.org/10.1111/j.1346-8138.2003.tb00378.x

[11] Pedersen, R.S., Hedelund, L., Poulsen, L.H., Bach, A. and Keller, J. (2013) Fatal KlippelTrénaunay Syndrome in a Child with Pulmonary Embolism. Ugeskr Laeger, 175, 21832184.

[12] Gloviczki, P., Stanson, A.W., Stickler, G.B., et al. (1991) Klippel-Trenaunay Syndrome: The Risks and Benefits of Vascular Interventions. Surgery, 110, 469-479.

Submit or recommend next manuscript to SCIRP and we will provide best service for you:

Accepting pre-submission inquiries through Email, Facebook, LinkedIn, Twitter, etc. A wide selection of journals (inclusive of 9 subjects, more than 200 journals)

Providing 24-hour high-quality service

User-friendly online submission system

Fair and swift peer-review system

Efficient typesetting and proofreading procedure

Display of the result of downloads and visits, as well as the number of cited articles

Maximum dissemination of your research work

Submit your manuscript at: http://papersubmission.scirp.org/

Or contact jbm@scirp.org 